\title{
Varicella and Dengue Co-Infection in a Child: Case Report
}

\author{
Kalenahalli Jagadishkumar ${ }^{1,{ }^{*}}$, Nanda Nataraj ${ }^{2}$ and Usha Rani Dasappa ${ }^{2}$ \\ ${ }^{1}$ Department of Pediatrics, JSS Medical College, JSS Academy of Higher Education and Research, Mysore, India \\ ${ }_{2}^{2}$ JSS Medical College, JSS Academy of Higher Education and Research, Mysore, India \\ "Corresponding author: Department of Pediatrics, JSS Medical College, JSS Academy of Higher Education and Research, Mysore, India. Email: jagdishmandya@gmail.com
}

Received 2019 March 06; Revised 2019 December 04; Accepted 2019 December 10.

\begin{abstract}
Co-infections are common in tropical countries and can be present with the overlapping of clinical features. The diagnosis of coinfection poses a challenge to the treating physician. We report a varicella child who was presented with persisting fever even after the formation of scabs along with conjunctival suffusion. Her platelets were persistently less than $50000 / \mathrm{mm}^{3}$ for 3 days and her serology was positive for the dengue infection.
\end{abstract}

Keywords: Varicella, Dengue, Co-Infection

\section{Introduction}

In developing countries like India, infectious diseases are the most important causes of morbidity and mortality (1). In tropical countries many co-infections are reported in various combinations (2). Therefore, the diagnosis of co-infections is a challenge to the treating clinician. If not timely treated, co-infections may lead to life-threatening consequences. Given that both varicella and dengue are endemic in India, it is possible that a child can be simultaneously infected by both these diseases. We report a child of varicella who was presented with persisting fever, conjunctival suffusion, with a decrease in platelet counts and her serology was positive for dengue infection.

\section{Case Presentation}

A five year old girl was brought with complaints of fever, rashes, and cold for the past week. The child had a continuous fever every day of the week. Rashes appeared on the day of onset of fever, first appeared on the trunk, later spread to extremities and it was papule-vesicular in nature. On examination she was febrile $\left(104^{\circ} \mathrm{F}\right), \mathrm{RR}=$ $32 / \mathrm{min}, \mathrm{PR}=140 / \mathrm{min}, \mathrm{BP}=100 / 50 \mathrm{~mm}$ of $\mathrm{Hg}, \mathrm{CFT}<3 \mathrm{sec}-$ onds, and oxygen saturation of $100 \%$ at room air. She had a bilateral conjunctival congestion and skin revealed non-erythematous black crusted lesions all over the body. Respiratory examination revealed bilateral crepitation's.
Other systems examination was unremarkable. Investigations at admission: $-\mathrm{Hb}=10.8 \mathrm{~g} / \mathrm{dL}, \mathrm{TLC}=8280 / \mathrm{mm}^{3}[\mathrm{n}=$ $60 \%, \mathrm{~L}=34 \%$, platelets $=2.3 \mathrm{lakh} / \mathrm{mm}^{3}, \mathrm{PCV}=34, \mathrm{AST}=135$ $\mathrm{U} / \mathrm{L}, \mathrm{ALT}=79 \mathrm{U} / \mathrm{L}$, and normal kidney functions. Chest $\mathrm{x}-$ ray was suggestive of bilateral pneumonia. Her peripheral smear for malarial parasite and Widal test were negative. Her blood culture was sterile. She was positive for dengue NS antigen by ELISA. She started on moxclav injections and intra venous Ringers lactate fluids according to the WHO protocol. The child continues to have high spikes of fever for two days. Her platelets decreased to $31000 / \mathrm{mm}^{3}$; PCV and haemoglobin increased to 37 and $12.4 \mathrm{gm} / \mathrm{dL}$ on the third day of admission. Her platelets showed a decreasing trend for another three days $\left(24000 / \mathrm{mm}^{3}, 29000 / \mathrm{mm}^{3}\right.$, $48000 / \mathrm{mm}^{3}$, respectively) and started increasing to reach 1.36 lakhs $/ \mathrm{mm}^{3}$ on the sixth day. She received five days of moxclav injections and was then discharged.

\section{Discussion}

Clinical diagnosis of varicella is based on the appearance and distribution of the vesicular lesions. The lesions are localized on the trunk and extremities. Initially, the rash consists of pruritic erythematous macules, which evolve through the popular stage to form clear, fluid-filled vesicles. While the initial lesions are crusting, new crops form for about five to seven days (3).

Our child was presented with classical features of varicella. According to the WHO conservative estimates, the

Copyright @ 2020, Journal of Comprehensive Pediatrics. This is an open-access article distributed under the terms of the Creative Commons Attribution-NonCommercial 4.0 International License (http://creativecommons.org/licenses/by-nc/4.0/) which permits copy and redistribute the material just in noncommercial usages, provided the original work is properly cited. 
global annual varicella disease burden would include 4.2 million severe complications leading to hospitalization and 4200 deaths (3). Varicella is usually self-limiting, however, it may be associated with severe complications, mediated either by the varicella zoster virus or secondary bacterial infections (3). Along with the classical clinical presentation of varicella, she also had a one week high grade fever, skin lesions without any signs of secondary infection, bilateral conjunctival suffusion, and respiratory symptoms. She was investigated for other causes of fever including dengue infection in view of conjunctival suffusion. In varicella, a fever generally lasts for three to five days, however, our child had a fever for more than a week (4). The most common infectious causes of fever in varicella are super-added infections of the skin due to Streptococcus pyogenes and Staphylococcus aureus $(4,5)$. However skin lesions were without any secondary bacterial infection in our child. In children, varicella pneumonia is a very rare complication of varicella and is common in adults (6). Chest x-ray revealed pneumonia in the present case. If it were bacterial she would have developed tachypnoea, which thankfully was not there and her total leucocyte count was normal. During the course of varicella, most of the lower airway infections are associated to other co-infections (6).

Throughout the world, around 3.9 billion people in 128 countries are at risk of contracting infection with dengue virus (7). The clinical features of dengue infection are difficult to distinguish from other illnesses found in tropical areas in the early phase of the illness (8). In view of fever for one week, along with bilateral conjunctival suffusion in a varicella child, we had the suspicion of dengue illness. Her platelets decreased over two days after admission and were persistently less than $50000 / \mathrm{mm}^{3}$ for three days. She was positive for NS antigen by ELISA and the diagnosis was consistent with the dengue hemorrhagic fever. In varicella, even though co-infections with bacterial complications, particularly skin superinfections, hand-foot-mouth disease, scrub typhus are reported, dengue co-infection was not reported in the literature (2, 4, 5, 9-11). Rebahi et al. (5), reported purulent meningitis in a child with varicella. Maitland reported three cases of meningococcal disease temporally associated with chickenpox (10). Francisco Espinoza-Gomez et al. (11), reported six cases of HIV-1 patients associated co-infection with the dengue virus from Mexico. In our child it is unlikely that varicella and dengue co-infections to occur concomitantly unless the patient is immunocompromised. Among immunocompromised states, HIV infection is the leading. In India, HIV infection is a substantial health problem and we probably we should have checked the HIV status of our child. In India both the diseases are endemic and it is possible to have both infections at the same time. Both varicella and dengue infection may lead to many complications if not diagnosed and treated promptly. Prompt recognition and treatment of co-infections should be undertaken to minimize morbidity and mortality. This report suggests the importance of knowing the epidemiological data of common diseases in the locality, natural course, as well as the significance of a thorough physical examination.

\subsection{Conclusions}

We should be aware of the natural course and classical clinical features of the commonly occurring diseases like dengue and varicella. Whenever there is change in the natural course or overlapping of clinical features it causes confusion in the diagnosis and concurrent co-infections should be strongly suspected.

\section{Footnotes}

Authors' Contribution: All authors (Kalenahalli Jagadishkumar, Nanda Nataraj, Usha rani Dasappa) were involved in managing, literature search, drafting, and writing the manuscript. Kalenahalli Jagadishkumar is the guarantor of the article.

Conflict of Interests: There is no conflict of interest in publishing this paper.

Funding/Support: None.

Informed Consent: Patient informed consent was taken.

\section{References}

1. Zaidi AK, Awasthi S, deSilva HJ. Burden of infectious diseases in South Asia. BMJ. 2004;328(7443):811-5. doi: 10.1136/bmj.328.7443.811. [PubMed: 15070639]. [PubMed Central: PMC383379].

2. Basheer A, Iqbal N, Mookkappan S, Anitha P, Nair S, Kanungo R, et al. Clinical and laboratory characteristics of dengue-orientia tsutsugamushi co-infection from a Tertiary Care Center in South India. Mediterr J Hematol Infect Dis. 2016;8(1). e2016028. doi 10.4084/MJHID.2016.028. [PubMed: 27413521]. [PubMed Central: PMC4928539].

3. Weekly epidemiological record (WER). 2014, [cited 2017 Jun 6]. Available from: http://www.who.int/wer.accesed.

4. Jain D, Viswanathan S, Shanmugam J. Lost in a haystack: The importance of physical re-examination. J Infect Public Health. 2014;7(5):4502. doi: 10.1016/j.jiph.2014.04.005. [PubMed: 24954067].

5. Rebahi H, Mouaffak Y, Soraa N, Younous S. Chickenpox complicated by pneumococcal meningitis: A rare coinfection. Arch Pediatr. 2014;21(11):1226-8. doi: 10.1016/j.arcped.2014.08.034. [PubMed: 25282451]. 
6. Hervas D, Henales V, Yeste S, Figuerola J, Hervas J. How frequent is varicella-associated pneumonia in children? Eur J Clin Microbiol Infect Dis. 2011;30(3):435-7. doi: 10.1007/s10096-010-1106-9. [PubMed: 21080022].

7. World Health Organization. Dengue and severe dengue. 2017, [cited 2017 Jun 06]. Available from: www.who.int/denguecontrol/en/.

8. Bhat RY, Varma C, Bhatt S. Dengue fever with co-infections: A case series in children. J Microbiol Infect Dis. 2014;4(5). doi: 10.5799/ahinjs.02.2014.S1.0144.

9. Na SY, Son YM, Lee HY, Baek JO, Roh JY, Lee JR. A case of Varicella combined with hand-foot-mouth disease in a healthy child. Ann Dermatol. 2009;21(1):98-101. doi: 10.5021/ad.2009.21.1.98. [PubMed: 20548870].
[PubMed Central: PMC2883384]

10. Maitland K. Temporal association of chickenpox and meningococcal disease in children: A report of three cases. Acta Paediatr. 2000;89(6):744-5. doi: 10.1080/080352500750044142. [PubMed: 10914977].

11. Espinoza-Gomez F, Delgado-Enciso I, Valle-Reyes S, Ochoa-Jimenez R, Arechiga-Ramirez C, Gamez-Arroyo JL, et al. Dengue virus coinfection in human immunodeficiency virus-1-infected patients on the West Coast of Mexico. Am J Trop Med Hyg. 2017;97(3):927-30. doi: 10.4269/ajtmh.17-0121. [PubMed: 28722631]. [PubMed Central: PMC5590606]. 